
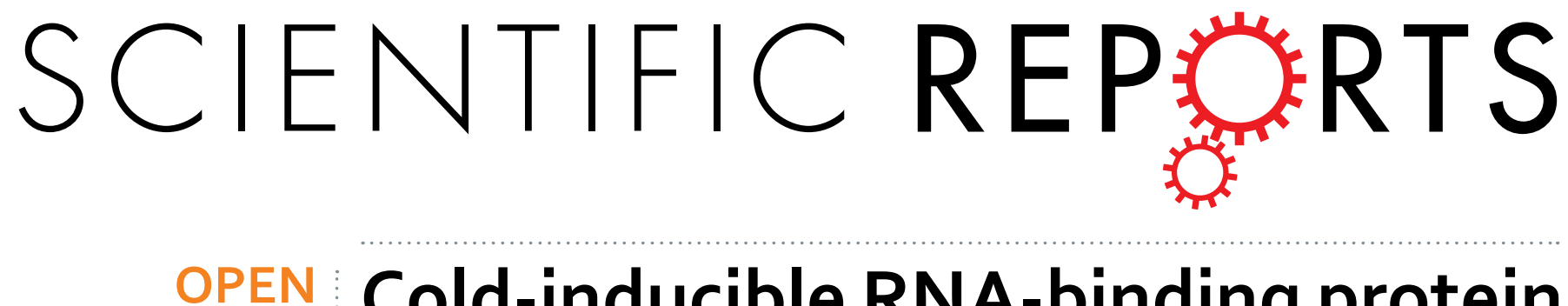

\title{
Cold-inducible RNA-binding protein (CIRP) causes sepsis-associated acute lung injury via induction of \\ endoplasmic reticulum stress
}

Received: 18 July 2016

Accepted: 19 December 2016

Published: 27 January 2017

\author{
Mohammad Moshahid Khan ${ }^{1,+}$, Weng-Lang Yang ${ }^{1,2,3}$, Max Brenner $^{1}$, \\ Alexandra Cerutti Bolognese ${ }^{2,3}$ \& Ping Wang ${ }^{1,2,3}$
}

Cold-inducible RNA-binding protein (CIRP), released into the circulation during sepsis, causes lung injury via an as yet unknown mechanism. Since endoplasmic reticulum (ER) stress is associated with acute lung injury (ALI), we hypothesized that CIRP causes ALI via induction of ER stress. To test this hypothesis, we studied the lungs of wild-type (WT) and CIRP knockout (KO) mice at $20 \mathrm{~h}$ after induction of sepsis by cecal ligation and puncture (CLP). WT mice had significantly more severe ALI than CIRP KO mice. Lung ER stress markers (BiP, pIRE1 $\alpha$, sXBP1, CHOP, cleaved caspase-12) were increased in septic WT mice, but not in septic CIRP KO mice. Effector pathways downstream from ER stress apoptosis, NF- $\kappa B$ (p65), proinflammatory cytokines (IL-6, IL-13), neutrophil chemoattractants (MIP-2, KC), neutrophil infiltration (MPO activity), lipid peroxidation (4-HNE), and nitric oxide (iNOS) - were significantly increased in WT mice, but only mildly elevated in CIRP KO mice. ER stress markers were increased in the lungs of healthy WT mice treated with recombinant murine CIRP, but not in the lungs of TLR4 KO mice. This suggests CIRP directly induces ER stress via TLR4 activation. In summary, CIRP induces lung ER stress and downstream responses to cause sepsis-associated ALI.

Sepsis is defined as life-threatening organ dysfunction caused by a dysregulated host response to infection and results in an estimated 5.3 million deaths worldwide every year ${ }^{1,2}$. Sepsis is often complicated by respiratory dysfunction due to acute lung injury (ALI), which is characterized by acute hypoxemic respiratory failure with bilateral pulmonary infiltrates and has an independent mortality rate of over $38 \%{ }^{3}$. Hematogenic ALI is generally thought to develop as a consequence of leukocyte and pulmonary endothelial cell activation by microbial products or cell injury-associated endogenous molecules ${ }^{4}$. However, the precise mechanisms underlying cellular activation and leading to ALI are still poorly understood, limiting the discovery of effective treatments for this condition.

Cold-inducible RNA-binding protein (CIRP) is a highly conserved nuclear protein whose gene expression is upregulated by hypoxia and mild hypothermia ${ }^{5,6}$. We have discovered that, during sepsis, CIRP translocates from the nucleus to the cytoplasm and is released into the circulation ${ }^{7}$. Once in the circulation, CIRP acts as a damage-associated molecular pattern molecule (DAMP) by binding to the TLR4-MD2 receptor complex to increase sepsis severity and mortality rate $\mathrm{r}^{7,8}$. We have recently shown that exogenous CIRP administered to healthy mice causes lung injury, as evidenced by vascular leakage, neutrophil infiltration, local production of TNF- $\alpha$ and IL-1 $\beta$, and activation of the NRLP3 inflammasome in lung vascular endothelial cells ${ }^{9}$. These observations suggest that CIRP plays a critical role in the development of sepsis-associated ALI. The precise mechanism by which CIRP causes lung injury, however, remains to be determined.

Protein folding and assembly normally take place in the endoplasmic reticulum $(\mathrm{ER})^{10}$. Unfolded or misfolded proteins are sensed by the ER transmembrane sentinel proteins IRE1 $\alpha$, PERK, and ATF6, triggering integrated signaling pathways that lead to the unfolded protein response (UPR) ${ }^{10-13}$. The UPR consists of transcriptional

${ }^{1}$ Center for Immunology and Inflammation, The Feinstein Institute for Medical Research, Manhasset, NY 11030, USA. ${ }^{2}$ Department of Surgery, Hofstra Northwell School of Medicine, Manhasset, NY 11030, USA. ${ }^{3}$ Elmezzi Graduate School of Molecular Medicine, Manhasset, NY 11030, USA. 'Present address: Department of Neurology, University of Tennessee Health Science Center, Memphis, TN, USA. Correspondence and requests for materials should be addressed to P.W. (email: pwang@northwell.edu) 
A

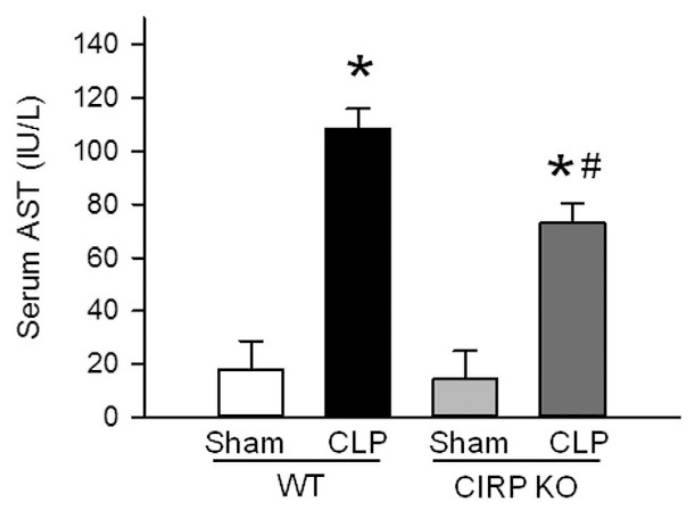

B

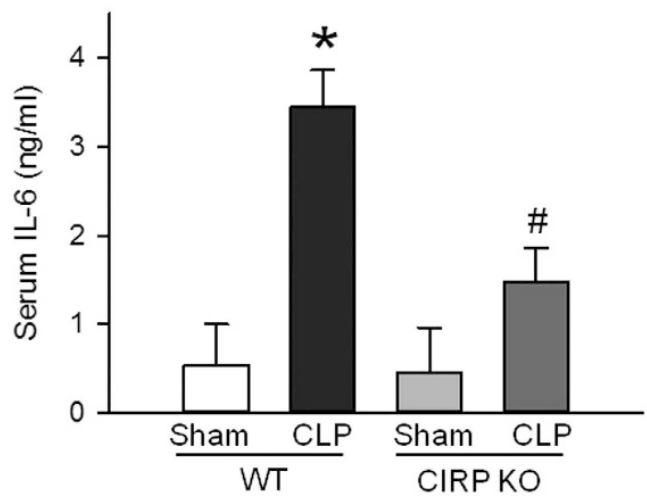

Figure 1. CIRP contributes to systemic injury in sepsis. At $20 \mathrm{~h}$ after CLP, serum levels of (A) AST (colorimetry) and (B) IL-6 (ELISA) were elevated in septic WT mice $\left({ }^{\star} P<0.05\right.$ vs. sham WT mice) and significantly reduced in septic CIRP KO mice $\left({ }^{\#} P<0.05\right.$ vs. septic WT mice). Data are expressed as last square mean \pm SEM. Sample sizes: $A S T$, sham $W T=4, C L P W T=8$, sham CIRP KO=4, CLP CIRP KO =8; IL-6, $W T=5, C L P W T=6$, sham $C I R P K O=4, C L P C I R P K O=7$.

and translational reprogramming that increase the expression of folding and chaperone proteins, cause cell cycle arrest, and down-regulate overall gene expression and protein synthesis ${ }^{11,14}$. If the changes in protein expression and chaperone proteins are unable to resolve the ER stress, apoptotic cascades are activated ${ }^{11,14}$. The IRE1 $\alpha$ pathway, in particular, integrates ER-stress signaling with the inflammatory response. Upon activation, IRE1 $\alpha$ homodimerizes, trans-autophosphorylates, and gives rise to spliced XBP1 (sXBP1) through endoribonuclease activity $^{11}$. sXBP1 is a potent transcription factor and a critical regulator of the UPR ${ }^{15}$. Once phosphorylated, the cytoplasmic domain of IRE1 $\alpha$ can recruit TRAF2 to activate JNK and IKK, leading to nuclear translocation of AP1 and NF- $\kappa$ B, and to the transcription of numerous genes involved in the inflammatory response ${ }^{16,17}$.

ER stress has been observed in sepsis and $\mathrm{ALI}^{10,18-23}$. Circulating endotoxin, commonly present in sepsis and sepsis-associated ALI, can induce ER stress via TLR4 ${ }^{12,19,24,25}$. ER stress then induces the release of proinflammatory cytokines via inflammasome activation ${ }^{13,26}$. Additionally, ER stress-induced apoptosis has been implicated in sepsis-associated lymphopenia and liver and myocardial dysfunction, three prominent features of sepsis ${ }^{12,24,25}$. Therefore, we hypothesized that CIRP released during sepsis leads to sepsis-associated ALI through the induction of ER stress and its downstream events in the lungs.

In this study, we demonstrate that CIRP triggers ER stress and augments inflammation, apoptosis, and histological injury in the lungs. Overall, these findings suggest that CIRP released during sepsis causes and increases the severity of ALI via induction of ER stress.

\section{Results}

CIRP increases sepsis severity. To determine the effects of CIRP on sepsis severity, we subjected WT and CIRP KO mice to CLP or sham operation and measured the serum levels of aspartate aminotransferase (AST) and IL-6, two biomarkers of injury and inflammation in sepsis and sepsis-associated ALI ${ }^{27,28}$. At $20 \mathrm{~h}$ after CLP, the serum levels of AST were 6.0-fold higher in septic WT mice than in sham WT mice (Fig. 1A). In septic CIRP KO mice, however, the serum levels of AST were $35.3 \%$ lower than those of septic WT mice (Fig. 1A). Likewise, serum levels of IL-6 were 6.3-fold higher in septic WT mice than in sham WT mice (Fig. 1B). In septic CIRP KO mice, however, the serum levels of IL- 6 were $64.7 \%$ lower than those of septic WT mice (Fig. 1B). Serum levels of AST and IL-6 in sham CIRP KO mice were similar to those of sham WT mice. These results indicate that CIRP is a significant contributor to systemic injury in sepsis.

CIRP is associated with increased severity of ALI. Lung tissues collected at $20 \mathrm{~h}$ after CLP were stained with hematoxylin and eosin (H\&E) for histological examination. Septic WT mice developed severe lung injury, with the presence of septal thickening, hyaline membranes, proteinaceous exudates and microthrombi, and the accumulation of neutrophils in the interstitium and alveolar spaces (Fig. 2A,B). Septic CIRP KO mice, however, had mostly preserved lung architecture, and their lung injury histological score was decreased by $75.5 \%$ compared to that of septic WT mice (Fig. 2A,B). These results show that CIRP is associated with ALI, demonstrated by increased histological injury in the lungs of septic mice.

CIRP is associated with apoptosis in ALI. In sepsis, the frequency of pulmonary microvascular endothelial cell apoptosis is increased and is thought to contribute to the endothelial cell dysfunction of ALI ${ }^{29,30}$. To determine whether CIRP contributes to apoptosis during ALI, we quantified the number of apoptotic events in the lungs of WT and CIRP KO mice collected $20 \mathrm{~h}$ after CLP. As expected, septic WT mice had significantly more apoptotic events than sham WT mice (by 8.2 -fold; Fig. 2C,D). The number of apoptotic events in the lungs of septic CIRP KO mice, however, was reduced by $65.2 \%$ compared with that of septic WT mice (Fig. 2C,D). There was 
A

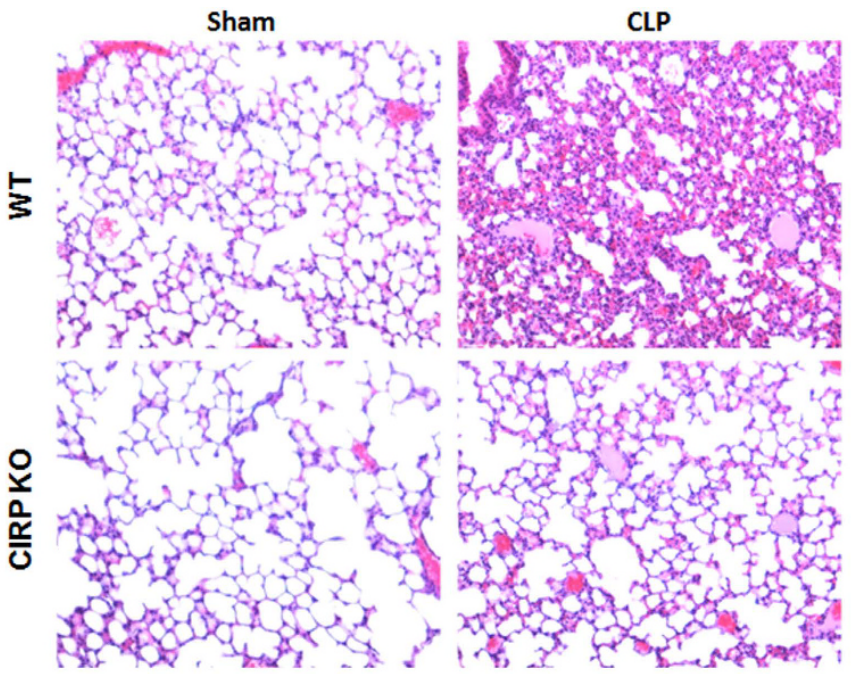

C
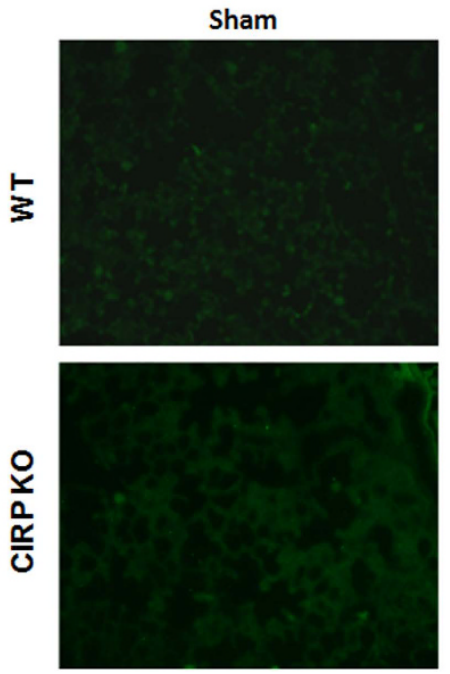
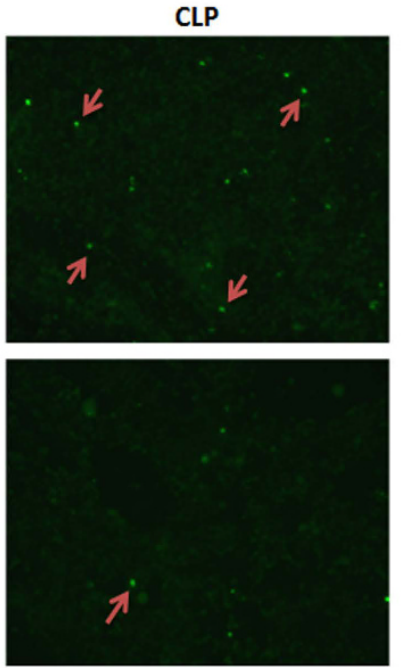

B

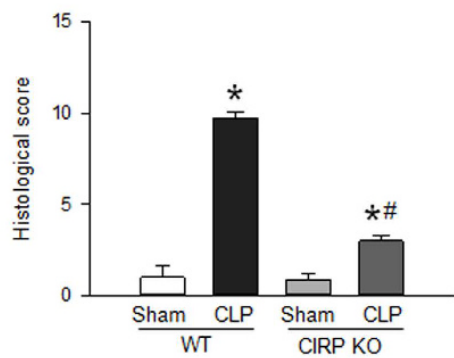

D

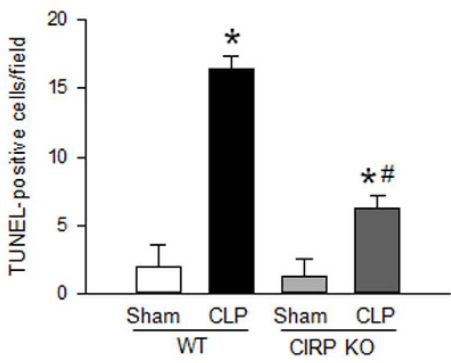

Figure 2. CIRP is associated with histological injury and increases lung apoptosis in ALI. (A) The lungs of WT and CIRP KO mice were collected at $20 \mathrm{~h}$ after CLP and examined histologically (H\&E). Compared with sham WT mice, septic WT mice developed severe lung injury, with septal thickening, hyaline membranes, proteinaceous exudates, microthrombi, and neutrophilic infiltration. Sham CIRP KO mice had normal lung architecture. Septic CIRP KO mice had some proteinaceous exudates and mild neutrophilic infiltration. (B) The lung injury histological score was elevated in septic WT mice $\left({ }^{*} P<0.05\right.$ vs. sham WT mice) and was significantly reduced in septic CIRP KO mice ( ${ }^{*} P<0.05$ vs. septic WT mice). (C) The lungs of WT and CIRP KO mice were collected at $20 \mathrm{~h}$ after CLP and subjected to the TUNEL assay. Compared with sham WT mice, the lungs of septic WT mice had a significant increase in the number of apoptotic events. The lungs of sham CIRP KO mice had no apoptosis. The lungs of septic CIRP KO mice had significantly less apoptotic events than those of septic WT mice. (D) The quantity of TUNEL-positive cells was elevated in septic WT mice $\left({ }^{*} P<0.05\right.$ vs. sham WT mice) and was significantly reduced in septic CIRP KO mice ( ${ }^{\#} P<0.05$ vs. septic WT mice). Representative sections; original magnification, 200X. Data are expressed as last square mean $\pm S E M$. Sample sizes: histological score, sham $W T=3, C L P W T=12$, sham $C I R P K O=7, C L P C I R P K O=12$; TUNEL staining, $W T=3, C L P W T=14$, sham CIRP KO=7, CLP CIRP KO=13.

no significant difference in the number of TUNEL-positive cells in sham WT and CIRP KO mice. These findings indicate that CIRP promotes apoptosis in the lungs of mice with sepsis-associated ALI.

CIRP increases ER stress in sepsis-associated ALI. ER stress is a known inducer of apoptosis ${ }^{10}$. To determine whether CIRP activates ER stress in ALI, we examined the protein expression levels of key ER stress markers in the lung at $20 \mathrm{~h}$ after CLP. Compared with the sham group, the lungs of WT mice with sepsis-associated ALI had significantly increased levels of the chaperone protein BiP (1.8-fold), phosphorylated (activated) ER stress sensor pIRE1 $\alpha$ (1.9-fold), spliced (activated) transcription factor sXBP1 (1.7-fold), and pro-apoptotic components CHOP (1.6-fold) and cleaved (activated) caspase-12 (1.3-fold) (Fig. 3A-E). In CIRP KO mice, however, these markers barely increased in the lungs of septic mice compared with the sham group (Fig. 3A-E). The 
A

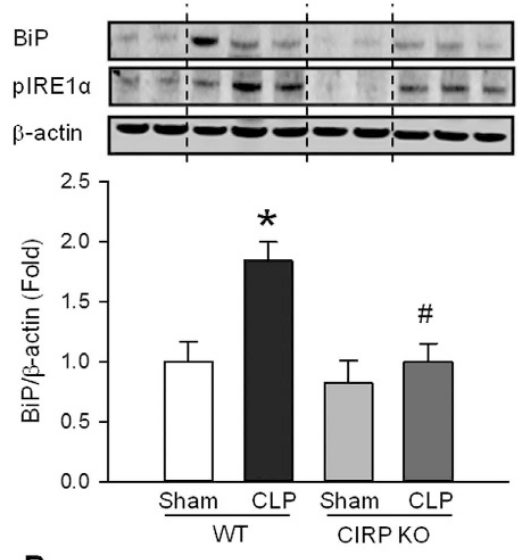

B

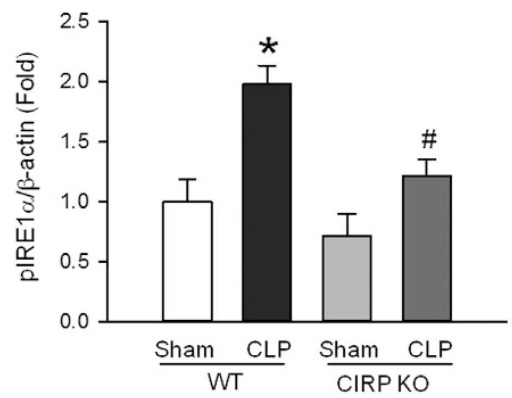

C
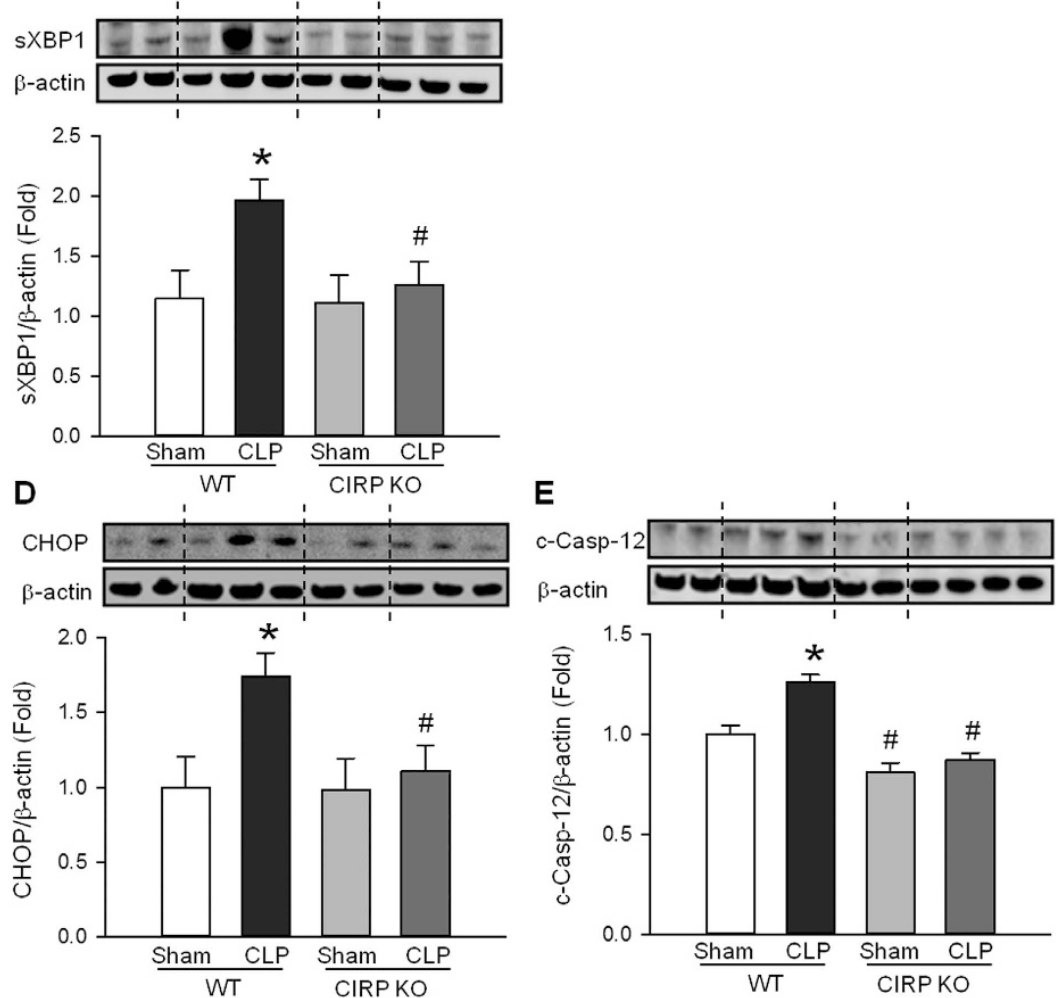

Figure 3. CIRP promotes ER stress during ALI. Lung protein levels of (A) BiP, (B) phosphorylated IRE1 $\alpha$ (pIRE1 $\alpha$ ), (C) spliced XBP1 (sXBP1), (D) CHOP and (E) cleaved caspase-12 (c-Casp-12) were determined by Western blotting (WB) in homogenates of lungs collected $20 \mathrm{~h}$ after CLP or sham operation. The levels of all five ER stress proteins were elevated in septic WT mice $\left({ }^{\star} P<0.05\right.$ vs. sham WT mice) and were significantly reduced in septic CIRP KO mice ( ${ }^{*} P<0.05 \mathrm{vs}$. septic WT mice). The dotted lines on the WB reflect the groups shown in the histogram below. Histograms show mean densitometric analysis of bands normalized for $\beta$-actin and relative to expression values in sham WT mice. Data are expressed as last square mean \pm SEM. Sample sizes: sham $W T=4, C L P W T=6$ sham $C I R P K O=4, C L P C I R P K O=6$.

baseline level of ER stress markers in sham CIRP KO mice was similar to that of sham WT mice. These results demonstrate that CIRP induces ER stress in sepsis-associated ALI.

CIRP mediates CHOP expression in pulmonary arteriolar endothelial cells in sepsis-associated ALI. To determine more precisely which cells undergo ER stress during ALI, we examined lungs collected at $20 \mathrm{~h}$ after CLP or sham operation for CHOP and CD31 expression by immunofluorescence. CD31 is a surface marker of endothelial cells (EC) that is shed upon EC activation by pro-inflammatory cytokines ${ }^{31-34}$. As expected, capillary expression of CD31 was decreased in the lungs of WT mice with CLP and, to a lesser degree, in CIRP KO mice with CLP. CHOP was markedly upregulated in the lungs of septic WT mice compared to sham WT mice (Fig. 4). CHOP was strongly expressed by pulmonary arteriolar endothelial cells and, to a lesser extent, microvascular endothelial cells, as determined by co-localization with CD31. CHOP expression was not detected in venular endothelial cells. CHOP expression was also not well detected in sham or septic CIRP KO mice (Fig. 4). These observations indicate that, in sepsis-associated ALI, CIRP leads to the expression of CHOP in endothelial cells, and that $\mathrm{CHOP}$ is predominantly induced in the pulmonary arterioles.

CIRP increases inflammation in sepsis-associated ALI. ER stress is a key inducer of proinflammatory cytokine and chemokine expression ${ }^{26,35,36}$. Therefore, we investigated the contribution of CIRP to inflammation in the lungs of mice subjected to CLP or sham operation. At $20 \mathrm{~h}$ after CLP, p65 (an NF- $\kappa \mathrm{B}$ subunit) was 1.7-fold higher in the lungs of septic WT mice compared with sham WT mice (Fig. 5A). The levels of p65 in septic CIRP KO mice, however, were not elevated when compared with sham CIRP KO mice (Fig. 5A). Next, we measured the levels of proinflammatory cytokines and chemokines known to play a significant role in sepsis-mediated ALI ${ }^{37}$. IL-6 and IL-1 $\beta$ levels were 2.6- and 2.1-fold higher, respectively, in the lungs of septic WT mice than in sham WT mice, and were reduced by $49.8 \%$ and $40.2 \%$, respectively, in septic CIRP KO mice compared to septic WT mice (Fig. 5B-C). Similarly, mRNA levels of MIP-2 and KC were 198.0- and 144.5-fold higher, respectively, in septic WT mice compared to sham WT mice. In septic CIRP KO mice, however, mRNA levels of MIP- 2 and KC were reduced by $95.9 \%$ and $81.1 \%$, respectively, compared to septic WT mice (Fig. 5D-E). MIP-2 and KC are potent neutrophil chemoattractants. Therefore, we also measured myeloperoxidase (MPO) activity, an indicator of the 


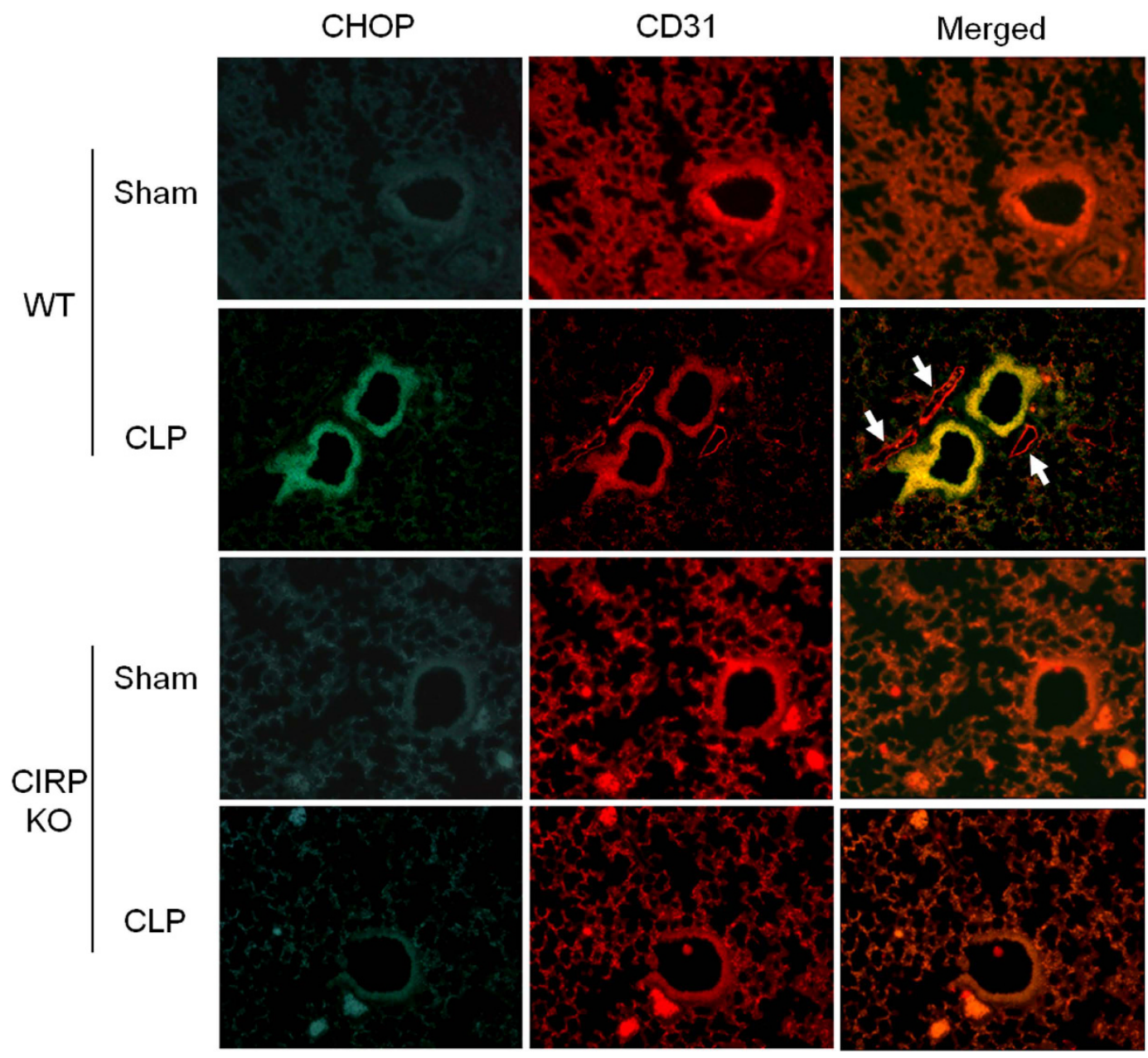

Figure 4. CIRP induces CHOP expression in pulmonary arteriolar and microvascular endothelial cells. The expression of CHOP (green) and CD31 (red) was determined by immunofluorescence in lungs collected $20 \mathrm{~h}$ after CLP or sham operation. High expression of CHOP was detected in pulmonary arteriolar endothelial cells of septic WT mice, but not in the other groups. CHOP was highly expressed in arteriolar endothelial cells (merged, yellow), and to a lesser extent in microvascular endothelial cells (merged, orange). CHOP was not detected in venular endothelial cells of septic WT mice (merged, white arrows). Representative sections; original magnification, $200 X$.

presence of activated neutrophils. MPO activity was 2.7-fold higher in septic WT mice than in sham WT mice (Fig. 5F). MPO activity in septic CIRP KO mice, however, was reduced by $67.3 \%$ compared to septic WT mice, indicating decreased neutrophil infiltration in the lungs of CIRP KO mice. Taken together, these results suggest that, similarly to ER stress, CIRP promotes NF- $\kappa$ B activation, inducing the expression and release of proinflammatory cytokines and chemokines and the influx of neutrophils, all of which are key elements in the pathobiology of sepsis-associated ALI.

CIRP increases oxidative stress and the expression of inducible nitric oxide synthase (iNOS) in sepsis-associated ALI. In response to ER stress, there is an increase in the production of reactive oxygen species $(\mathrm{ROS})^{38}$. ROS can cause lipid peroxidation and result in tissue damage ${ }^{39}$. CIRP has also been associated with increased tissue levels of ROS ${ }^{40}$. To determine whether CIRP promotes oxidative stress during ALI, we quantified 4-hydroxy-2-nonenal (4-HNE), a marker of lipid peroxidation, in the lungs of mice subjected to CLP or sham operation. At $20 \mathrm{~h}$ after CLP, the levels of 4 -HNE were 1.9-fold higher in septic WT mice than in sham WT mice (Fig. 6A). The levels of 4-HNE in septic CIRP KO mice, however, were not elevated when compared to sham CIRP KO mice (Fig. 6A). The ER stress-induced production of ROS is mediated by iNOS ${ }^{41}$. Therefore, we quantified iNOS mRNA in the lung tissues of WT and CIRP KO mice collected $20 \mathrm{~h}$ after CLP or sham operation and found that it was 13.7-fold higher in septic WT mice compared with sham WT mice (Fig. 6B). Expression of iNOS mRNA in septic CIRP KO mice, however, was not increased and was similar to that of sham CIRP KO mice (Fig. 6B). Sham CIRP KO and sham WT mice had similar baseline levels of 4-HNE and iNOS. These results indicate that CIRP is an important contributor to the production of ROS during ALI, possibly via induction of iNOS following ER stress. 

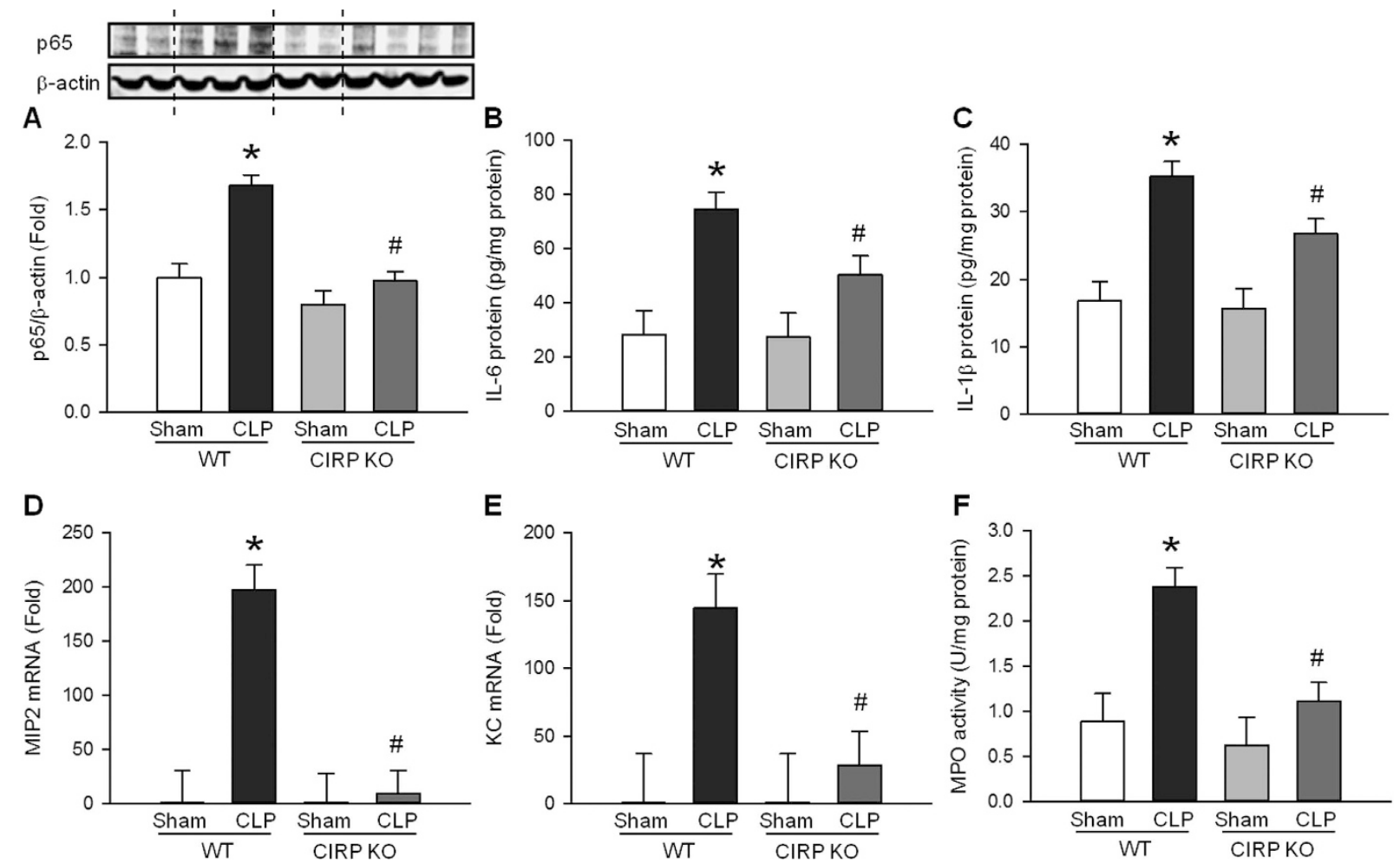

Figure 5. CIRP increases NF- $\kappa B$, cytokine, and chemokine expression, and neutrophil infiltration in ALI. (A) Lung levels of NF- $\kappa$ B p65 (WB) were elevated in septic WT mice $\left({ }^{\star} P<0.05\right.$ vs. sham WT mice) and were significantly reduced in septic CIRP KO mice ( ${ }^{\#} P<0.05$ vs. septic WT mice). At $20 \mathrm{~h}$ after CLP, the lung protein expression of (B) IL-6 and (C) IL-1 $\beta$ were measured by ELISA, the lung mRNA expression of (D) MIP-2 and (E) KC were measured by real time-PCR, and (F) lung MPO activity was measured by colorimetry. The lung expression of proinflammatory cytokines and chemokines, as well as neutrophil infiltration as measured by MPO activity, were elevated in septic WT mice $\left({ }^{\star} P<0.05\right.$ vs. sham WT mice) and were significantly reduced in septic CIRP KO mice ( ${ }^{\#} P<0.05$ vs. septic WT mice). The dotted lines on the WB reflect the groups shown in the histogram below. Data are expressed as last square mean \pm SEM. Sample sizes: sham $W T=2-4, C L P W T=2-8$, sham CIRP KO=2-4, CLP CIRP KO=4-8.

CIRP induces ER stress via TLR4. We have previously shown that CIRP aggravates sepsis via its binding to the TLR4-MD2 receptor complex ${ }^{7}$. To determine how CIRP regulates ER stress, we administered recombinant murine (rm) CIRP or vehicle (phosphate-buffered saline solution) intravenously to healthy WT and TLR4 KO mice. At $20 \mathrm{~h}$ after injection, we collected the lungs and measured protein levels of BiP, pIRE1 $\alpha$, and sXBP1. Compared to vehicle, administration of rmCIRP resulted in a statistically significant induction of BiP (1.6-fold), pIRE1 $\alpha$ (1.4-fold), and sXBP1 (1.5-fold) in the lungs of WT mice (Fig. 7A-C). Administration of rmCIRP to TLR4 KO mice, however, failed to induce BiP, pIRE1 $\alpha$, or sXBP1 (Fig. 7D-F). These findings indicate that CIRP is sufficient to induce ER stress, and suggest that CIRP regulates ER stress via activation of the TLR4 receptor.

\section{Discussion}

CIRP is an RNA-binding protein normally present in the cell nucleus. We have previously shown that in sepsis and septic shock, CIRP translocates from the nucleus to the cytosol and is subsequently released into the circulation, where it acts as a DAMP to increase disease severity and mortality ${ }^{7}$. We have also shown that healthy mice injected with CIRP develop lung injury ${ }^{9}$, suggesting that the CIRP released during sepsis contributes to the development of sepsis-associated ALI. In the present study, we discovered a previously unknown link between CIRP and ER stress in the pathogenesis of ALI. Several studies have suggested a role for ER stress in sepsis and ALI pathobiology $y^{10,18,19}$. Here we show that CIRP is critical for the sepsis-induced ER stress response in the lungs of septic mice. CIRP was required for the induction of five key ER stress proteins: the chaperone protein $\mathrm{BiP}$, the phosphorylated (activated) form of the ER stress sensor IRE1 $\alpha$, the spliced (activated) form of transcription factor XBP1, and the pro-apoptotic components CHOP and cleaved (activated) Casp-12. These components of the ER stress response and UPR are fundamental for activation of downstream cascades that ultimately cause the release of proinflammatory mediators and apoptosis ${ }^{42-45}$. CHOP, for example, contributes to the myocardial dysfunction often present in sepsis by causing cardiomyocyte apoptosis ${ }^{45}$. Additionally, mice with sepsis induced by CLP or lipopolysaccharide (LPS) injection that are deficient in CHOP have lower levels of proinflammatory cytokines, less splenocyte apoptosis, improved bacterial clearance, and increased survival rates ${ }^{18}$. Likewise, septic mice that are deficient in Casp-12 also have decreased levels of proinflammatory cytokines and increased 
A

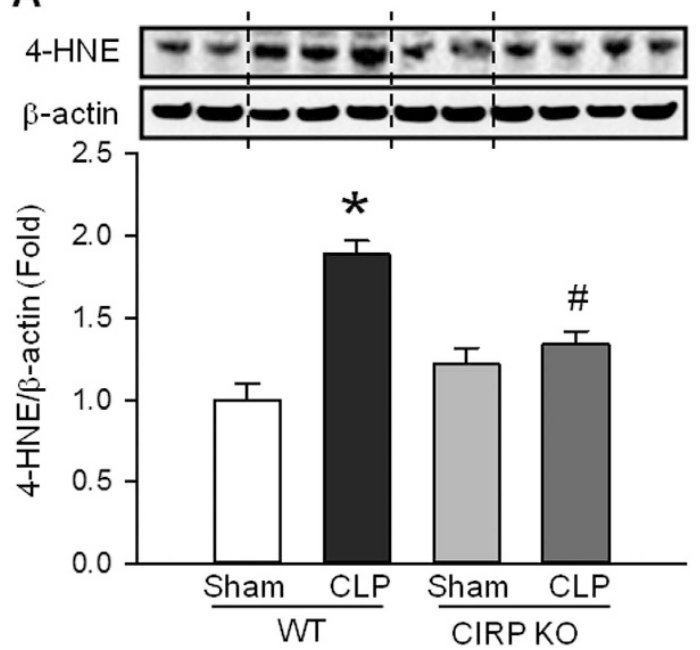

B

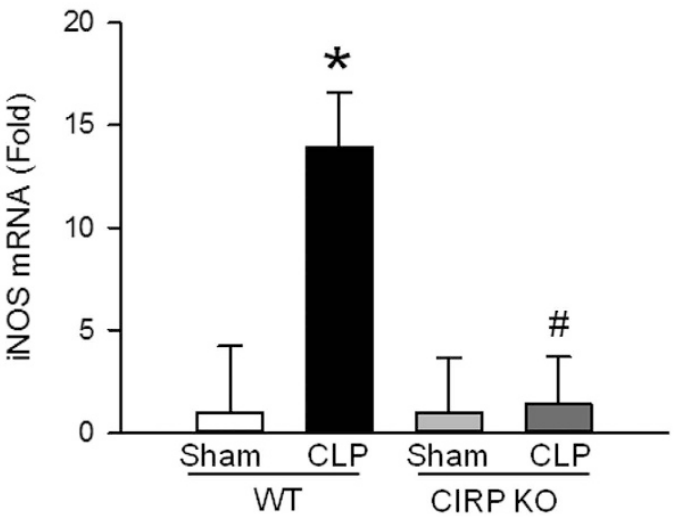

Figure 6. CIRP increases lipid peroxidation and iNOS in ALI. At $20 \mathrm{~h}$ after CLP, the lung levels of (A) 4-HNE (WB) and (B) iNOS (RT-PCR) were elevated in septic WT mice $\left({ }^{\star} P<0.05\right.$ vs. sham WT mice) and were significantly reduced in septic CIRP KO mice ( ${ }^{P} P<0.05 \mathrm{vs}$. septic WT mice). The dotted lines on the WB reflect the groups shown in the histogram below. Histograms show data normalized for $\beta$-actin and relative to expression values in sham WT mice. Data are expressed as last square mean \pm SEM. Sample sizes: 4 -HNE, sham $W T=4$, $C L P W T=6$, sham $C I R P K O=4, C L P C I R P K O=7 ; i N O S, W T=2, C L P W T=3$, sham $C I R P K O=3, C L P C I R P$ $K O=4$.

survival after $\mathrm{CLP}^{46}$. Although two studies have suggested otherwise ${ }^{47,48}$, a large number of studies have implicated Casp-12 in the regulation of ER stress-induced apoptosis. Casp-12 KO mice are resistant to ER stress-induced apoptosis ${ }^{49}$, cultured cortical neurons from Casp-12 KO mice are resistant to amyloid- $\beta$ neurotoxicity ${ }^{49}$, and pharmacologic modulation of Casp-12 has been shown to regulate ER stress-induced apoptosis ${ }^{50-53}$.

Among the three ER stress sensors, we focused on the IRE1 $\alpha$ pathway because it integrates ER-stress signaling with the inflammatory response, which is the most prominent and clinically relevant feature of ALI. During ER stress, IRE1 $\alpha$ associates with the adaptor protein TRAF2 to activate NF- $\kappa B$ and AP-1, two key transcription factors in inflammation and immunity ${ }^{16,17,19,54}$. Upon activation, NF- $\kappa B$ and AP-1 translocate to the nucleus, where they induce the expression of proinflammatory cytokines and chemokines known to promote sepsis-associated $\mathrm{ALI}^{55}$. Accordingly, we observed an association between CIRP and expression of the NF- $\kappa \mathrm{B}$ protein p65. We also observed that CIRP increased the levels of IL-6, IL-1 $\beta$, MIP-2, and KC in the lungs of septic mice. MIP- 2 and KC are potent chemoattractants that regulate neutrophil migration to the lungs ${ }^{56}$. Indeed, we noticed that CIRP was also associated with increased influx of neutrophils to the lungs. Taken together, these observations suggest that CIRP-induced inflammation and neutrophil influx in ALI may be mediated by ER stress. Our observations are supported by published studies that showed reduced levels of proinflammatory cytokines in septic mice deficient for the CHOP and caspase-12 components of the UPR ${ }^{18,21,46}$.

We found that CIRP induced ER stress in pulmonary endothelial cells. This finding is in agreement with the fact that, during sepsis-associated ALI, endothelial cells are directly exposed to circulating DAMPs and endotoxin, causing endothelial cell activation leading to increased surface expression of adhesion molecules, dismantling of tight junctions, expression and release of proinflammatory cytokines and chemokines, and acquisition of a prothrombotic phenotype ${ }^{9,57,58}$. We have recently demonstrated that CIRP alone is sufficient to activate pulmonary endothelial cells, leading to increased surface expression of E-selectin and ICAM-1, assembly and activation of the Nlrp3 inflammasome, and release of IL-1 $\beta^{9}$. Interestingly, ER stress is also known to induce the Nlrp3 inflammasome $e^{13,26}$. We observed decreased intensity of CD31 straining in the lungs of mice subjected to CLP, suggesting that endothelial cells had been activated and undergone shedding of CD31's extracellular domain ${ }^{32-34}$.

We observed that sepsis only increased lung apoptosis in the presence of CIRP. Apoptosis is a well-known late result of ER activation, and CHOP is upregulated and induces apoptosis in the lungs of mice with LPS-induced $\mathrm{ALI}^{21}$. Furthermore, pulmonary endothelial cell apoptosis is a significant cause of increased vascular permeability contributing to edema, thrombosis, and neutrophil migration in sepsis-associated $\mathrm{ALI}^{30,59,60}$. These observations suggest that ER stress induced by CIRP may aggravate sepsis via apoptosis-associated endothelial cell dysfunction. Pulmonary endothelial cell apoptosis in ALI is dependent on NADPH-oxidase and iNOS activities $^{30}$. In our study, we found a significant association between CIRP, ROS, and iNOS in the lungs of septic mice. CIRP has been reported to induce ROS ${ }^{40}$, and we have shown that CIRP causes activation of the ROS-producing NADPH-oxidase in lung endothelial cells $s^{9}$. ER stress is also known to result in increased production of ROS $^{38,61}$. ROS-induced peroxidation of biomembrane phospholipids, leading to the formation of 4-HNE, is a relevant and biologically significant consequence of ROS production. Additionally, lipid peroxidation works as an amplification loop to further increase ER stress ${ }^{62}$. Additionally, ER stress-triggered production of ROS is mediated, at least in part, by upregulation of iNOS ${ }^{41}$. In our study, iNOS upregulation required the presence of CIRP. Therefore, 


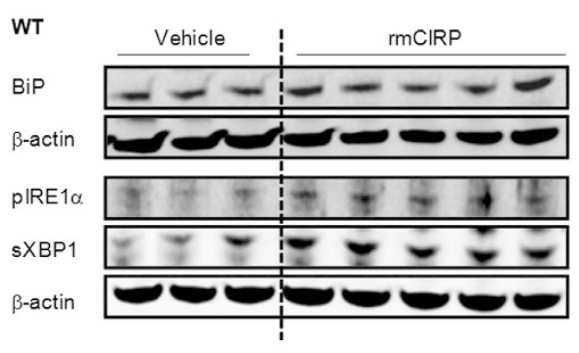

A

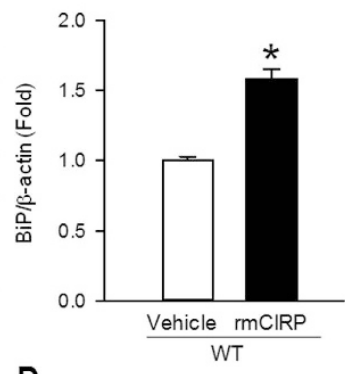

TLR4 KO

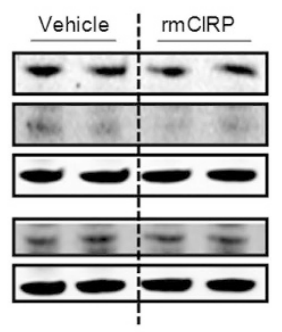

D

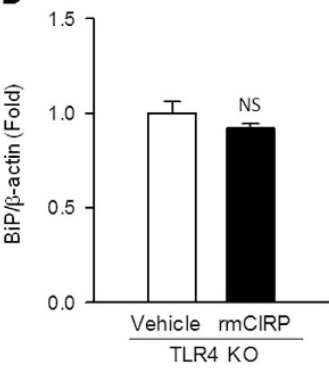

B

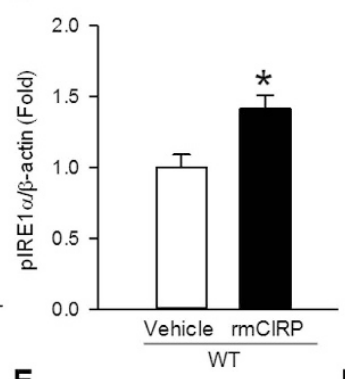

E

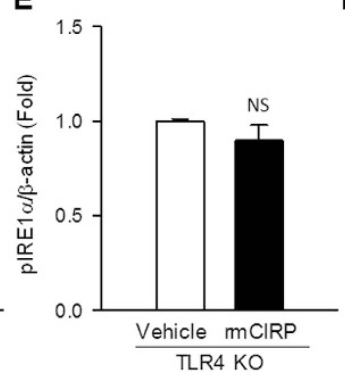

C
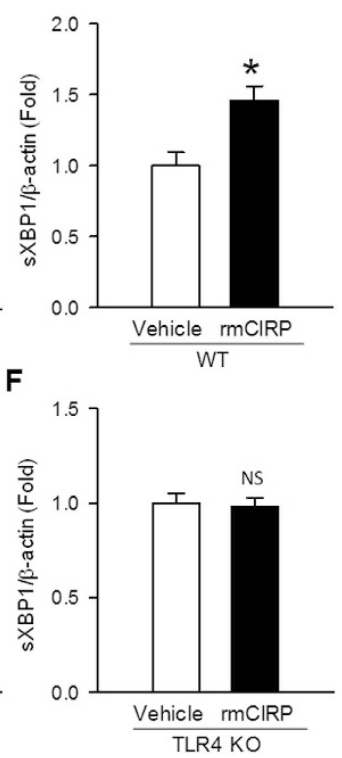

Figure 7. CIRP-induced ER stress is TLR4-dependent. Lung levels of (A) BiP, (B) pIRE1 $\alpha$, and (C) sXBP1 proteins were significantly elevated in healthy WT mice treated with $\operatorname{rmCIRP}\left({ }^{*} P<0.05\right)$, confirming that CIRP induces ER stress. Lung levels of (D) BiP, (E) pIRE1 $\alpha$, and (F) sXBP1 proteins, however, were not increased in healthy TLR4 KO mice treated with rmCIRP (NS, not significant), indicating that ER stress induction by CIRP requires TLR4. Western blotting of homogenates from lungs collected $20 \mathrm{~h}$ after rmCIRP intravenous administration. The dotted lines on the WB reflect the groups shown in the histogram below. Data are expressed as mean \pm SEM. Sample sizes: $W T$, vehicle $=3, r m C I R P=5 ; T L R 4 K O$, vehicle $=2, r m C I R P=2$.

it is possible that the CIRP-induced production of ROS in the lungs of septic mice was in fact mediated by CIRP-induced ER stress via iNOS upregulation.

We have shown that injection of exogenous CIRP leads to ALI via CIRP-caused pulmonary endothelial cell activation ${ }^{9}$. As such, we decided to focus our investigation on endothelial cells and observed that CHOP expression was particularly prominent in pulmonary arteriolar endothelial cells, intermediate in microvascular endothelial cells, and not detected in venular endothelial cells. This CHOP expression gradient from the pulmonary artery to the pulmonary vein indicates preferential ER stress activation in the arterial pulmonary circulation and suggests a pre-pulmonary origin for CIRP. Macrophages are a known source of CIRP ${ }^{7}$. As such, it is possible that in sepsis most of the circulating CIRP is released by resident mononuclear phagocytic cells in the two largest solid organs, the liver and spleen.

This is the first time that mice lacking the CIRP protein have been studied for sepsis-associated ALI. We found that CIRP KO mice developed less severe sepsis overall, as measured by serum levels of AST and IL-6, two disease severity biomarkers in sepsis and sepsis-associated ALI ${ }^{27,28}$. This finding is consistent with studies that found an association between circulating levels of CIRP and sepsis severity in mice and in humans ${ }^{7,8}$, and also with studies that found an association between ER stress activation and CLP- and LPS-induced ALI severity and mortality rates $^{18,21,46}$. Additionally, decreased levels of IL-6 and other systemic injury biomarkers have also been reported after blockade of CIRP in a number of experimental models of human diseases associated with acute inflammation $^{7,9,63,64}$. We also observed that the presence of the CIRP protein was critical for the development of histological features typical of ALI associated with sepsis in humans and with CLP in mice, namely septal thickening, hyaline membranes, proteinaceous exudates, microthrombi, and neutrophilic infiltrates ${ }^{65}$. CIRP-induced tissue damage has been reported in other models of human disease $e^{63,66,67}$, and is likely the result of the convergence of CIRP's endothelial-activating, proinflammatory, and pro-apoptotic effects.

We have previously shown that CIRP binds the TLR4-MD2 complex with high affinity ${ }^{7}$. Additionally, TLR4 agonists are known inducers of ER stress ${ }^{19,24,25,68,69}$. These two observations suggest that CIRP might cause ER stress via its binding to TLR4. Indeed, we have now shown that CIRP activation of ER stress is TLR4-dependent. Endotoxemia, which is often present in sepsis, can also induce ER stress via activation of TLR4 ${ }^{19,25}$. Studies show that a functional TLR4 is required for the development of ALI secondary to endotoxemia ${ }^{70}$, hemorrhagic shock $^{71,72}$, burns ${ }^{73}$, and paraquat poisoning ${ }^{74}$. Since CIRP is one of TLR4's known agonists, it is possible that CIRP also plays a role in the development of ALI after these insults.

In conclusion, we discovered a novel pathway linking CIRP to the induction of ER stress in the development of sepsis-associated ALI (Fig. 8). This new pathway is TLR4-dependent and involves local induction of proinflammatory cytokines and chemokines, neutrophil influx, and apoptosis. Future studies should consider agents targeting CIRP as a potential new therapeutic strategy to treat patients with sepsis. 


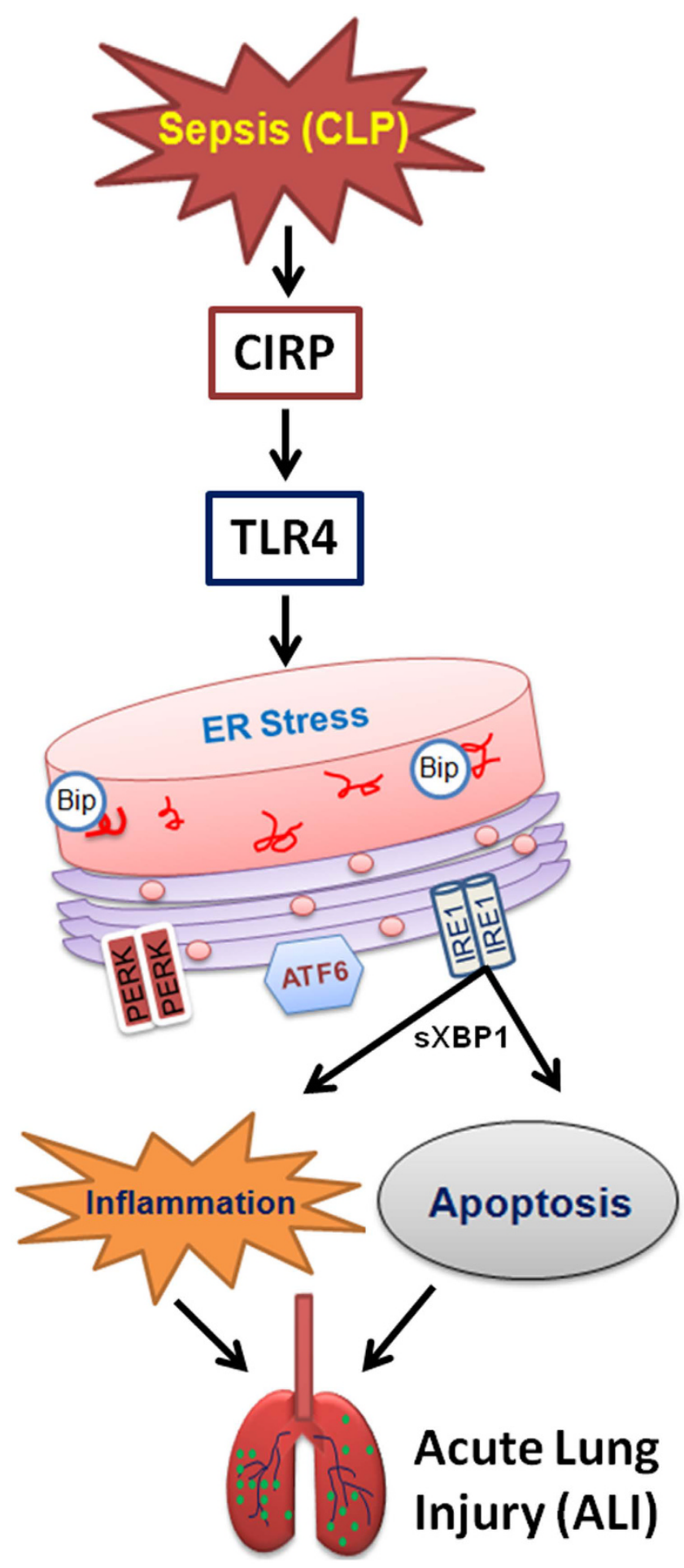

Figure 8. Proposed sequence of events in ALI pathogenesis. During sepsis (CLP), CIRP is released and interacts with TLR4. The CIRP-TLR4 interaction leads to activation of ER stress, causing inflammation and apoptosis, ultimately resulting in acute lung injury (ALI).

\section{Methods}

Animals. Male 8- to 12-week-old wild type (WT, C57BL/6), CIRP KO (Cirbp ${ }^{-1-}$ ), and TLR4 KO (Tlr4 ${ }^{-1-}$ )

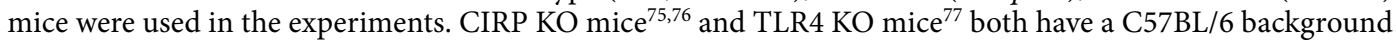
and were kind gifts from Dr. Jun Fujita (Kyoto University, Japan) and Dr. Huan Yang (FIMR), respectively. Mice were housed in temperature-controlled rooms with 12-h light cycles and fed a standard mouse diet. All experiments involving live animals were performed in accordance with the National Institutes of Health guidelines for use of experimental animals, and approved by the FIMR Institutional Animal Care and Use Committee. 


\begin{tabular}{|l|c|c|c|c|}
\hline Protein & Gene & RefSeq & Forward primer & Reverse primer \\
\hline iNOS & Nos2 & NM_010927 & GGCAAACCCAAGGTCTACGTT & GAGCACGCTGAGTACCTCATTG \\
\hline IL-6 & Il6 & NM_031168 & CCGGAGAGGAGACTTCACAG & CAGAATTGCCATTGCACAAC \\
\hline MIP-2 & Cxcl2 & NM_009140.2 & CATCCAGAGCTTGAGTGTGA & CTTTGGTTCTTCCGTTGAGG \\
\hline KC & Cxcl1 & NM_008176 & GCTGGGATTCACCTCAAGAA & ACAGGTGCCATCAGAGCAGT \\
\hline
\end{tabular}

Table 1. Primer sequences used for cDNA amplification.

Animal model of sepsis. Mice were anesthetized with isoflurane and placed in the supine position. The ventral abdomen was shaved and cleaned with $10 \%$ povidone-iodine wash and CLP was performed as described previously ${ }^{7}$. Briefly, a $1-\mathrm{cm}$ midline incision was performed. The cecum was exposed, ligated just distal to the ileocecal valve to avoid intestinal obstruction, and punctured twice with a 22-gauge needle. A small amount of cecal content was then expressed from the perforated sites and the ligated cecum was returned to the peritoneal cavity. The laparotomy wound was suture-closed in layers. Sham operated animals underwent the same procedure with the exception that the cecum was neither ligated nor punctured. Immediately after surgery, animals received a subcutaneous injection of $1 \mathrm{ml}$ normal saline. At $20 \mathrm{~h}$ after CLP, mice were euthanized for collection of blood and lungs.

Measurements of serum enzymes and cytokines. Whole-blood samples were centrifuged at $4,000 \mathrm{~g}$ for $10 \mathrm{~min}$ to collect serum. The activity of aspartate aminotransferase (AST) was determined using a commercial assay kit (Pointe Scientific, Lincoln Park, MI). Serum and tissue levels of interleukin $1 \beta$ (IL-1 $1 \beta$ ) and interleukin 6 (IL-6) were determined using mouse-specific ELISA kits (BD Biosciences, San Diego, CA). All assays were carried out according to manufacturer's instructions.

Histological evaluation of lung injury and TUNEL staining. Upper and lower lobe lung samples were collected $20 \mathrm{~h}$ after CLP, fixed in $10 \%$ formalin, embedded in paraffin, microsectioned at $4 \mu \mathrm{m}$, and stained with hematoxylin-eosin. Lung injury score was then assessed in a blinded fashion using a semi-quantitative light microscopy evaluation as previously described ${ }^{28}$. For terminal deoxynucleotidyl transferase dUTP nick-end labeling (TUNEL) staining, fluorescence staining was performed using a commercially available in situ Cell Death Detection Kit (Roche Diagnostics, Indianapolis, IN). The assay was conducted according to the manufacturer's instructions. Results are expressed as the average number of TUNEL-positive staining cells per 200X magnification field.

Western blotting. Lungs from each group of mice were homogenized in $500 \mu$ l lysis buffer ( $10 \mathrm{mM}$ Tris-HCL $\mathrm{pH} 7.5,120 \mathrm{mM} \mathrm{NaCl}, 1 \% \mathrm{NP}-40,1 \%$ sodium deoxycholate, and $1 \%$ Triton X-100) containing protease and phosphatase inhibitor cocktails (Roche) using a sonicator on ice. Samples were centrifuged at $14,000 \mathrm{~g}$ for $20 \mathrm{~min}$ at $4^{\circ} \mathrm{C}$, and the supernatants were collected. Sample protein concentrations were measured using the BCA protein assay kit (Pierce Biotechnology, Rockford, IL), and 65- $\mu$ g protein samples were separated by electrophoresis on $4-12 \%$ gradient Bis-Tris gels and transferred to nitrocellulose membranes. After blocking with $0.1 \%$ casein, membranes were incubated with primary antibodies against BiP, pIRE1 $\alpha, \mathrm{CHOP}$, cleaved caspase-12 (Cell signaling Technology, Danvers, MA), sXBP1, NF- $\kappa$ p65 (Santa Cruz Biotechnology, Santa Cruz, CA), 4-HNE (Abcam, Cambridge, MA), or $\beta$-actin (Sigma-Aldrich, St. Louis, MO). 4-HNE is stable, making its quantification more reliable than direct quantification of ROS

After washing, membranes were incubated with the appropriate fluorescent-conjugated secondary antibodies. Bands were detected using an Odyssey FC Imaging system (LI-COR, Lincoln, NE). Band intensities were quantified with densitometry and represented as fold changes relative to controls. The corrected band intensity data from two Western blots was used to plot each histogram.

Immunofluorescence confocal microscopy. Fixed lung histological sections were first stained with unconjugated anti-mouse CHOP (clone L63F7) monoclonal antibody (Cell Signaling), then stained with Alexa Fluor $^{\circledR}$ 488-labeled polyclonal anti-mouse IgG $(\mathrm{H}+\mathrm{L}) \mathrm{F}\left(\mathrm{ab}^{\prime}\right)_{2}$ antibody fragment (Cell Signaling), and then stained for ECs with phycoerythrin (PE)-labeled anti-mouse CD31 antibody (clone MEC13.3) (Biolegend, San Diego, CA). The stained lung section was imaged by confocal microscope with excitation at $480 \mathrm{~nm}$ for green fluorescence $(\mathrm{CHOP})$ and at $540 \mathrm{~nm}$ for red fluorescence $(\mathrm{CD} 31)$.

Real-time reverse transcription polymerase chain reaction analysis. RNA was extracted from lung tissues using TRIzol (Invitrogen, Carlsbad, CA) and reverse-transcribed into cDNA using murine leukemia virus reverse transcriptase (ThermoFisher Scientific, Waltham, MA). PCR reactions were carried out in $25 \mu \mathrm{l}$ containing $0.08 \mu \mathrm{mol}$ of each forward and reverse primer (Table 1), $5 \mu \mathrm{l} \mathrm{cDNA}, 6.5 \mu \mathrm{l} \mathrm{H}_{2} \mathrm{O}$, and $12.5 \mu \mathrm{l}$ SYBR Green PCR Master Mix (ThermoFisher Scientific). Amplification was conducted in duplicates using a 7300 real-time thermocycler (Applied Biosystems, Foster City, CA) with the thermal profile of $50^{\circ} \mathrm{C}$ for 2 min and $95^{\circ} \mathrm{C}$ for $10 \mathrm{~min}$, followed by $45 \mathrm{cycles}$ of $95^{\circ} \mathrm{C}$ for $15 \mathrm{~s}$ and $60^{\circ} \mathrm{C}$ for $1 \mathrm{~min}$. The level of mouse $\beta$-actin mRNA was used for normalization. Relative expression of mRNA was determined using the $2^{(-\Delta \Delta C t)}$ method. The primer sequences are listed as following: 
Myeloperoxidase activity assay. Lung tissues were sonicated in $50 \mathrm{mM}$ potassium phosphate buffer containing $0.5 \%$ hexadecyltrimethylammonium bromide. After centrifugation, the supernatant was diluted in reaction solution containing o-dianisidine hydrochloride and $\mathrm{H}_{2} \mathrm{O}_{2}$. The rate of change in optical density (OD) for $1 \mathrm{~min}$ was measured at $460 \mathrm{~nm}$ to calculate MPO activity, as described previously ${ }^{7}$.

Administration of rmCIRP. The expression and purification of rmCIRP has been previously described ${ }^{7}$. Briefly, rmCIRP was expressed in E. coli, purified, and validated by SDS-PAGE, Western blotting, and liquid chromatography tandem mass spectrometry. rmCIRP $(5 \mathrm{mg} / \mathrm{kg} \mathrm{BW})$ or vehicle (phosphate-buffered saline solution, PBS) was administered to healthy WT and TLR4 KO mice through the jugular vein. Lungs tissues were harvested at $20 \mathrm{~h}$ post-injection for the measurement of ER stress markers.

Statistical analysis. Results are reported as least square mean \pm SEM. Sample sizes assumed a two-tailed statistical significance of 0.05 or less and a power of 0.8 . Sample sizes for sham groups included a reduced number of animals because measurements in these groups are significantly more homogeneous. Specific measurements with smaller sample sizes were sometimes used because of limited amount of serum/tissue left, and reflect random sampling rather than exclusion. Analyses of multiple groups were carried out using two-way ANOVA with multiple comparisons using Dunnett's method with WT sham as the control group. Comparisons between two groups were carried out using two-tailed Student's t-test or the Mann-Whitney test, depending on the distribution.

\section{References}

1. Fleischmann, C. et al. Assessment of global incidence and mortality of hospital-treated sepsis. Current estimates and limitations. Am J Respir Crit Care Med 193, 259-272, doi: 10.1164/rccm.201504-0781OC (2016).

2. Singer, M. et al. The third international consensus definitions for sepsis and septic shock (Sepsis-3). JAMA 315, 801-810, doi: 10.1001/jama.2016.0287 (2016)

3. Rubenfeld, G. D. et al. Incidence and outcomes of acute lung injury. The New England journal of medicine 353, 1685-1693, doi: 10.1056/NEJMoa050333 (2005).

4. Matthay, M. A., Ware, L. B. \& Zimmerman, G. A. The acute respiratory distress syndrome. J Clin Invest 122, 2731-2740, doi: 10.1172/JCI60331 (2012).

5. Wellmann, S. et al. Oxygen-regulated expression of the RNA-binding proteins RBM3 and CIRP by a HIF-1-independent mechanism. J Cell Sci 117, 1785-1794, doi: 10.1242/jcs.01026 (2004).

6. Al-Fageeh, M. B. \& Smales, C. M. Alternative promoters regulate cold inducible RNA-binding (CIRP) gene expression and enhance transgene expression in mammalian cells. Mol Biotechnol 54, 238-249, doi: 10.1007/s12033-013-9649-5 (2013).

7. Qiang, X. et al. Cold-inducible RNA-binding protein (CIRP) triggers inflammatory responses in hemorrhagic shock and sepsis. Nat Med 19, 1489-1495, doi: 10.1038/nm.3368 (2013).

8. Zhou, Y. et al. The cold-inducible RNA-binding protein (CIRP) level in peripheral blood predicts sepsis outcome. PLoS One 10, e0137721, doi: 10.1371/journal.pone.0137721 (2015)

9. Yang, W. L. et al. Cold-inducible RNA-binding protein causes endothelial dysfunction via activation of Nlrp3 inflammasome. Sci Rep 6, 26571, doi: 10.1038/srep26571 (2016).

10. Khan, M. M., Yang, W. L. \& Wang, P. Endoplasmic reticulum stress in sepsis. Shock 44, 294-304, doi: 10.1097/SHK. 0000000000000425 (2015).

11. Walter, P. \& Ron, D. The unfolded protein response: from stress pathway to homeostatic regulation. Science 334, 1081-1086, doi: 10.1126/science.1209038 (2011)

12. Afrazi, A. et al. Toll-like receptor 4-mediated endoplasmic reticulum stress in intestinal crypts induces necrotizing enterocolitis. J Biol Chem 289, 9584-9599, doi: 10.1074/jbc.M113.526517 (2014).

13. Lebeaupin, C. et al. ER stress induces NLRP3 inflammasome activation and hepatocyte death. Cell Death Dis 6, e1879, doi: 10.1038/ cddis.2015.248 (2015).

14. Hetz, C., Chevet, E. \& Harding, H. P. Targeting the unfolded protein response in disease. Nat Rev Drug Discov 12, 703-719, doi: $10.1038 / \mathrm{nrd} 3976(2013)$.

15. Kaufman, R. J. \& Cao, S. Inositol-requiring $1 / \mathrm{X}$-box-binding protein 1 is a regulatory hub that links endoplasmic reticulum homeostasis with innate immunity and metabolism. EMBO Mol Med 2, 189-192, doi: 10.1002/emmm.201000076 (2010)

16. Urano, F. et al. Coupling of stress in the ER to activation of JNK protein kinases by transmembrane protein kinase IRE1. Science 287, 664-666 (2000)

17. Hu, P., Han, Z., Couvillon, A. D., Kaufman, R. J. \& Exton, J. H. Autocrine tumor necrosis factor alpha links endoplasmic reticulum stress to the membrane death receptor pathway through IRE1alpha-mediated NF-kappaB activation and down-regulation of TRAF2 expression. Mol Cell Biol 26, 3071-3084, doi: 10.1128/MCB.26.8.3071-3084.2006 (2006).

18. Ferlito, M. et al. Hydrogen sulfide [corrected] increases survival during sepsis: protective effect of CHOP inhibition. J Immunol 192, 1806-1814, doi: 10.4049/jimmunol.1300835 (2014).

19. Kim, H. J. et al. Inhibition of endoplasmic reticulum stress alleviates lipopolysaccharide-induced lung inflammation through modulation of NF-kappaB/HIF-1alpha signaling pathway. Sci Rep 3, 1142, doi: 10.1038/srep01142 (2013).

20. Diao, L. et al. Burn plus lipopolysaccharide augments endoplasmic reticulum stress and NLRP3 inflammasome activation and reduces PGC-1alpha in liver. Shock 41, 138-144, doi: 10.1097/SHK.0000000000000075 (2014).

21. Endo, M., Oyadomari, S., Suga, M., Mori, M. \& Gotoh, T. The ER stress pathway involving CHOP is activated in the lungs of LPStreated mice. J Biochem 138, 501-507, doi: 10.1093/jb/mvil43 (2005).

22. Toltl, L. J., Austin, R. C. \& Liaw, P. C. Activated protein C modulates inflammation, apoptosis and tissue factor procoagulant activity by regulating endoplasmic reticulum calcium depletion in blood monocytes. J Thromb Haemost 9, 582-592, doi: 10.1111/j.1538-7836.2010.04177.x (2011).

23. Chen, G. et al. Thioredoxin-1 increases survival in sepsis by inflammatory response through suppressing endoplasmic reticulum stress. Shock 46, 67-74, doi: 10.1097/SHK.0000000000000570 (2016).

24. Okla, M. et al. Activation of Toll-like receptor (TLR) 4 attenuates adaptive thermogenesis via endoplasmic reticulum stress. J Biol Chem, doi: 10.1074/jbc.M115.677724 (2015).

25. Sodhi, C. P. et al. Intestinal epithelial TLR-4 activation is required for the development of acute lung injury after trauma/hemorrhagic shock via the release of HMGB1 from the gut. J Immunol 194, 4931-4939, doi: 10.4049/jimmunol.1402490 (2015).

26. Bronner, D. N. et al. Endoplasmic reticulum stress activates the inflammasome via NLRP3- and caspase-2-driven mitochondrial damage. Immunity 43, 451-462, doi: 10.1016/j.immuni.2015.08.008 (2015).

27. Miguel-Bayarri, V. et al. Prognostic value of the biomarkers procalcitonin, interleukin- 6 and C-reactive protein in severe sepsis. Med Intensiva 36, 556-562, doi: 10.1016/j.medin.2012.01.014 (2012).

28. Hirano, Y. et al. Neutralization of osteopontin attenuates neutrophil migration in sepsis-induced acute lung injury. Crit Care 19, 53 , doi: 10.1186/s13054-015-0782-3 (2015). 
29. Rudkowski, J. C. et al. Roles of iNOS and nNOS in sepsis-induced pulmonary apoptosis. Am J Physiol Lung Cell Mol Physiol 286, L793-800, doi: 10.1152/ajplung.00266.2003 (2004).

30. Gill, S. E., Rohan, M. \& Mehta, S. Role of pulmonary microvascular endothelial cell apoptosis in murine sepsis-induced lung injury in vivo. Respir Res 16, 109, doi: 10.1186/s12931-015-0266-7 (2015).

31. Bantikassegn, A., Song, X. \& Politi, K. Isolation of epithelial, endothelial, and immune cells from lungs of transgenic mice with oncogene-induced lung adenocarcinomas. Am J Respir Cell Mol Biol 52, 409-417, doi: 10.1165/rcmb.2014-0312MA (2015).

32. Stewart, R. J., Kashour, T. S. \& Marsden, P. A. Vascular endothelial platelet endothelial adhesion molecule-1 (PECAM-1) expression is decreased by TNF-alpha and IFN-gamma. Evidence for cytokine-induced destabilization of messenger ribonucleic acid transcripts in bovine endothelial cells. J Immunol 156, 1221-1228 (1996).

33. Rival, Y., Del Maschio, A., Rabiet, M. J., Dejana, E. \& Duperray, A. Inhibition of platelet endothelial cell adhesion molecule-1 synthesis and leukocyte transmigration in endothelial cells by the combined action of TNF-alpha and IFN-gamma. J Immunol 157, 1233-1241 (1996).

34. Shaw, S. K. et al. Reduced expression of junctional adhesion molecule and platelet/endothelial cell adhesion molecule-1 (CD31) at human vascular endothelial junctions by cytokines tumor necrosis factor-alpha plus interferon-gamma Does not reduce leukocyte transmigration under flow. Am J Pathol 159, 2281-2291 (2001).

35. Tam, A. B., Mercado, E. L., Hoffmann, A. \& Niwa, M. ER stress activates NF-kappaB by integrating functions of basal IKK activity, IRE1 and PERK. PLoS One 7, e45078, doi: 10.1371/journal.pone.0045078 (2012).

36. Willy, J. A., Young, S. K., Stevens, J. L., Masuoka, H. C. \& Wek, R. C. CHOP links endoplasmic reticulum stress to NF-kappaB activation in the pathogenesis of nonalcoholic steatohepatitis. Mol Biol Cell 26, 2190-2204, doi: 10.1091/mbc.E15-01-0036 (2015).

37. Hwaiz, R. et al. Rac1 signaling regulates sepsis-induced pathologic inflammation in the lung via attenuation of Mac-1 expression and CXC chemokine formation. J Surg Res 183, 798-807, doi: 10.1016/j.jss.2013.02.045 (2013).

38. Santos, C. X. et al. Endoplasmic reticulum stress and Nox-mediated reactive oxygen species signaling in the peripheral vasculature: potential role in hypertension. Antioxid Redox Signal 20, 121-134, doi: 10.1089/ars.2013.5262 (2014).

39. Galley, H. F. Oxidative stress and mitochondrial dysfunction in sepsis. Br J Anaesth 107, 57-64, doi: 10.1093/bja/aer093 (2011).

40. Sakurai, T. et al. Cold-inducible RNA-binding protein promotes the development of liver cancer. Cancer Sci 106, 352-358, doi: $10.1111 /$ cas.12611 (2015)

41. Hsieh, Y. H. et al. Differential endoplasmic reticulum stress signaling pathways mediated by iNOS. Biochem Biophys Res Commun 359, 643-648, doi: 10.1016/j.bbrc.2007.05.154 (2007).

42. Smith, J. A. et al. Endoplasmic reticulum stress and the unfolded protein response are linked to synergistic IFN-beta induction via X-box binding protein 1. Eur J Immunol 38, 1194-1203, doi: 10.1002/eji.200737882 (2008).

43. Jian, B. et al. Activation of endoplasmic reticulum stress response following trauma-hemorrhage. Biochim Biophys Acta 1782, 621-626, doi: 10.1016/j.bbadis.2008.08.007 (2008).

44. Qiu, Q. et al. Toll-like receptor-mediated IRE1alpha activation as a therapeutic target for inflammatory arthritis. EMBO J 32, 2477-2490, doi: 10.1038/emboj.2013.183 (2013).

45. Zhang, B. et al. Cortistatin protects myocardium from endoplasmic reticulum stress induced apoptosis during sepsis. Mol Cell Endocrinol 406, 40-48, doi: 10.1016/j.mce.2015.02.016 (2015).

46. Saleh, M. et al. Enhanced bacterial clearance and sepsis resistance in caspase-12-deficient mice. Nature 440, 1064-1068, doi: 10.1038/nature04656 (2006).

47. Obeng, E. A. \& Boise, L. H. Caspase- 12 and caspase-4 are not required for caspase-dependent endoplasmic reticulum stress-induced apoptosis. J Biol Chem 280, 29578-29587, doi: 10.1074/jbc.M502685200 (2005).

48. Di Sano, F. et al. Endoplasmic reticulum stress induces apoptosis by an apoptosome-dependent but caspase 12-independent mechanism. J Biol Chem 281, 2693-2700, doi: 10.1074/jbc.M509110200 (2006).

49. Nakagawa, T. et al. Caspase-12 mediates endoplasmic-reticulum-specific apoptosis and cytotoxicity by amyloid-beta. Nature 403, 98-103, doi: 10.1038/47513 (2000).

50. Zhang, Q. et al. Caspase-12 is involved in stretch-induced apoptosis mediated endoplasmic reticulum stress. Apoptosis 21, 432-442, doi: 10.1007/s10495-016-1217-6 (2016).

51. Guo, Y. S. et al. 17beta-Estradiol inhibits ER stress-induced apoptosis through promotion of TFII-I-dependent Grp78 induction in osteoblasts. Lab Invest 94, 906-916, doi: 10.1038/labinvest.2014.63 (2014).

52. Tong, Q. et al. Inhibition of endoplasmic reticulum stress-activated IRE1alpha-TRAF2-caspase-12 apoptotic pathway is involved in the neuroprotective effects of telmisartan in the rotenone rat model of Parkinson's disease. Eur J Pharmacol 776, 106-115, doi: 10.1016/j.ejphar.2016.02.042 (2016)

53. Martinez, J. A. et al. Calpain and caspase processing of caspase-12 contribute to the ER stress-induced cell death pathway in differentiated PC12 cells. Apoptosis 15, 1480-1493, doi: 10.1007/s10495-010-0526-4 (2010).

54. Kaneko, M., Niinuma, Y. \& Nomura, Y. Activation signal of nuclear factor-kappa B in response to endoplasmic reticulum stress is transduced via IRE1 and tumor necrosis factor receptor-associated factor 2. Biol Pharm Bull 26, 931-935 (2003).

55. Jin, L. Y. et al. Effect of siRNA against NF-kappaB on sepsis-induced acute lung injury in a mouse model. Mol Med Rep 10, 631-637, doi: 10.3892/mmr.2014.2299 (2014)

56. Shanley, T. P. et al. Requirement for C-X-C chemokines (macrophage inflammatory protein-2 and cytokine-induced neutrophil chemoattractant) in IgG immune complex-induced lung injury. J Immunol 158, 3439-3448 (1997).

57. Vandenbroucke, E., Mehta, D., Minshall, R. \& Malik, A. B. Regulation of endothelial junctional permeability. Ann N Y Acad Sci 1123, 134-145, doi: 10.1196/annals.1420.016 (2008).

58. Ince, C. et al. The endothelium in sepsis. Shock 45, 259-270, doi: 10.1097/SHK.0000000000000473 (2016).

59. Aschkenasy, G., Bromberg, Z., Raj, N., Deutschman, C. S. \& Weiss, Y. G. Enhanced Hsp70 expression protects against acute lung injury by modulating apoptotic pathways. PLoS One 6, e26956, doi: 10.1371/journal.pone.0026956 (2011).

60. Ma, T. et al. The endoplasmic reticulum stress-mediated apoptosis signal pathway is involved in sepsis-induced abnormal lymphocyte apoptosis. Eur Surg Res 41, 219-225, doi: 10.1159/000135631 (2008).

61. Abuaita, B. H., Burkholder, K. M., Boles, B. R. \& O'Riordan, M. X. The endoplasmic reticulum stress sensor inositol-requiring enzyme lalpha augments bacterial killing through sustained oxidant production. MBio 6, e00705, doi: 10.1128/mBio.00705-15 (2015).

62. Cubillos-Ruiz, J. R. et al. ER stress sensor XBP1 controls anti-tumor immunity by disrupting dendritic cell homeostasis. Cell 161, 1527-1538, doi: 10.1016/j.cell.2015.05.025 (2015).

63. Godwin, A. et al. Blocking cold-inducible RNA-binding protein protects liver from ischemia-reperfusion injury. Shock 43, 24-30, doi: $10.1097 /$ SHK.0000000000000251 (2015).

64. Li, G. et al. Cold-inducible RNA-binding protein plays a central role in the pathogenesis of abdominal aortic aneurysm in a murine experimental model. Surgery 159, 1654-1667, doi: 10.1016/j.surg.2016.01.007 (2016)

65. Matute-Bello, G., Frevert, C. W. \& Martin, T. R. Animal models of acute lung injury. Am J Physiol Lung Cell Mol Physiol 295, L379-399, doi: 10.1152/ajplung.00010.2008 (2008).

66. Zhou, M., Yang, W. L., Ji, Y., Qiang, X. \& Wang, P. Cold-inducible RNA-binding protein mediates neuroinflammation in cerebral ischemia. Biochim Biophys Acta doi: 10.1016/j.bbagen.2014.02.027 (2014).

67. Rajayer, S. R. et al. Cold-inducible RNA-binding protein is an important mediator of alcohol-induced brain inflammation. PLoS One 8, e79430, doi: 10.1371/journal.pone.0079430 (2013). 
68. Thomas, K. C. et al. Contributions of TRPV1, endovanilloids, and endoplasmic reticulum stress in lung cell death in vitro and lung injury. Am J Physiol Lung Cell Mol Physiol 302, L111-119, doi: 10.1152/ajplung.00231.2011 (2012).

69. Martinon, F., Chen, X., Lee, A. H. \& Glimcher, L. H. TLR activation of the transcription factor XBP1 regulates innate immune responses in macrophages. Nat Immunol 11, 411-418, doi: 10.1038/ni.1857 (2010).

70. Jeyaseelan, S., Chu, H. W., Young, S. K., Freeman, M. W. \& Worthen, G. S. Distinct roles of pattern recognition receptors CD14 and Toll-like receptor 4 in acute lung injury. Infect Immun 73, 1754-1763, doi: 10.1128/IAI.73.3.1754-1763.2005 (2005).

71. Barsness, K. A. et al. Hemorrhage-induced acute lung injury is TLR-4 dependent. Am J Physiol Regul Integr Comp Physiol 287, R592-599, doi: 10.1152/ajpregu.00412.2003 (2004).

72. Lv, T., Shen, X., Shi, Y. \& Song, Y. TLR4 is essential in acute lung injury induced by unresuscitated hemorrhagic shock. J Trauma 66, 124-131, doi: 10.1097/TA.0b013e318181e555 (2009).

73. Krzyzaniak, M. et al. Burn-induced acute lung injury requires a functional Toll-like receptor 4. Shock 36, 24-29, doi: 10.1097/ SHK.0b013e318212276b (2011).

74. Liu, W., Shan, L. P., Dong, X. S. \& Liu, Z. Toll-like receptor 4 implicated in acute lung injury induced by paraquat poisoning in mice. Int J Clin Exp Med 7, 3392-3397 (2014).

75. Sakurai, T. et al. Cirp protects against tumor necrosis factor-alpha-induced apoptosis via activation of extracellular signal-regulated kinase. Biochim Biophys Acta 1763, 290-295, doi: 10.1016/j.bbamcr.2006.02.007 (2006).

76. Masuda, T. et al. Cold-inducible RNA-binding protein (Cirp) interacts with Dyrk1b/Mirk and promotes proliferation of immature male germ cells in mice. Proc Natl Acad Sci USA 109, 10885-10890, doi: 10.1073/pnas.1121524109 (2012).

77. Yang, H. et al. A critical cysteine is required for HMGB1 binding to Toll-like receptor 4 and activation of macrophage cytokine release. Proc Natl Acad Sci USA 107, 11942-11947, doi: 10.1073/pnas.1003893107 (2010).

\section{Acknowledgements}

This study was supported by NIH grants R01GM053008, R01GM057468, and R35GM118337 (PW). We thank Xiaoling Qiang and Jian Hua Li for their technical assistance on providing recombinant murine CIRP for this study. We also thank Mahendar L. Ochani for his assistance with the CLP and sham surgeries.

\section{Author Contributions}

W.-L.Y., M.M.K. and P.W. conceived and designed the experiments; M.M.K. and A.B.C. performed the experiments; M.M.K. and M.B. analyzed the data; M.M.K. and M.B. wrote the manuscript and prepared the figures; and W.-L.Y. and P.W. reviewed the manuscript and supervised the research. All authors read and approved the final manuscript.

\section{Additional Information}

Competing financial interests: One of the authors $(\mathrm{PW})$ is an inventor of the PCT applications WO/2010/120726: "Treatment of inflammatory diseases by the inhibition of cold shock proteins" and US 61/881,798: "Peptides inhibiting cold-inducible RNA binding protein activity." These patent applications cover the fundamental concept of inhibiting CIRP for the treatment of inflammatory diseases. The other authors have no conflict of interest.

How to cite this article: Khan, M. M. et al. Cold-inducible RNA-binding protein (CIRP) causes sepsisassociated acute lung injury via induction of endoplasmic reticulum stress. Sci. Rep. 7, 41363; doi: 10.1038/ srep41363 (2017).

Publisher's note: Springer Nature remains neutral with regard to jurisdictional claims in published maps and institutional affiliations.

(c) (i) This work is licensed under a Creative Commons Attribution 4.0 International License. The images or other third party material in this article are included in the article's Creative Commons license, unless indicated otherwise in the credit line; if the material is not included under the Creative Commons license, users will need to obtain permission from the license holder to reproduce the material. To view a copy of this license, visit http://creativecommons.org/licenses/by/4.0/

(c) The Author(s) 2017 